\title{
Rice Yield Responses in Bangladesh to Large-scale Atmospheric Oscillation Using Multifactorial Model
}

\section{Bonosri Ghose}

Department of Disaster Management, Begum Rokeya University, Rangpur-5400, Bangladesh

Abu Reza Md. Towfiqul Islam ( $\nabla$ towfiq_dm@brur.ac.bd)

Begum Rokeya University https://orcid.org/0000-0001-5779-1382

\section{Roquia Salam}

Department of Disaster Management, Begum Rokeya University, Rangpur-5400, Bangladesh

\section{Shamsuddin Shahid}

Department of Water and Environmental Engineering, School of Civil Engineering, Universiti Teknologi Malaysia (UTM), 81310 Johor, Malaysia

\section{Md. Kamruzzaman}

Bangladesh Rice Research Institute, Gazipur 1701, Bangladesh

\section{Samiran Das}

School of Hydrology and Water Resources, Nanjing University of Information Science and Technology, Nanjing 210044, China

\section{Ahmed Elbeltagi}

Agricultural Engineering Dept., Faculty of Agriculture, Mansoura University, Mansoura 35516, Egypt

\section{Mohammed Abdus Salam}

Department of Environmental Science and Disaster Management, Noakhali Science and Technology University, Noakhali 3814, Bangladesh

\section{Research Article}

Keywords: Climate-derived yield index, multifactorial model, Indian ocean dipole, climate anomalies, Bangladesh, Aus rice yield

Posted Date: May 11th, 2021

DOl: https://doi.org/10.21203/rs.3.rs-385886/v1

License: (c) (i) This work is licensed under a Creative Commons Attribution 4.0 International License. Read Full License 
Version of Record: A version of this preprint was published at Theoretical and Applied Climatology on July 15th, 2021. See the published version at https://doi.org/10.1007/s00704-021-03725-7. 


\title{
1 Rice yield responses in Bangladesh to large-scale atmospheric oscillation using \\ multifactorial model
}

1

\footnotetext{
${ }^{5}$ Agricultural Engineering Dept., Faculty of Agriculture, Mansoura University, Mansoura 35516, Egypt

${ }^{6}$ College of Environmental and Resource Sciences, Zhejiang University, Hangzhou 310058, China

${ }^{7}$ Department of Environmental Science and Disaster Management, Noakhali Science and Technology

University, Noakhali 3814, Bangladesh

*Corresponding author: towfiq_dm@brur.ac.bd; sshahid@utm.edu
}

\author{
Abu Reza Md. Towfiqul Islam, PhD \\ Shamsuddin Shahid, PhD \\ ORCID: 0000-0001-5779-1382
}

21 Abstract:

This paper intends to explore rice yield fluctuations to large-scale atmospheric circulation indices (LACIs) in Bangladesh. The annual dataset of climate-derived yield index (CDYI), estimated using principal component analysis of Aus rice yield data of 23 districts, and five LACIs for the period 1980-2017 were used for this purpose. The key outcomes of the study were as follows: (1) three sub-regions of Bangladesh, northern, northwestern, and northeastern, showed different kinds of CDYI anomalies; (2) the CDYI time series in northern and northeastern regions exhibited a substantial 6-year fluctuation, whereas a 2.75 to 3-year fluctuation predominated the northwestern region; (3) rice yield showed the highest sensitivity of LACIs in the 
northern region; (4) Indian Ocean dipole (IOD) and East Central Tropical Pacific SST (Nino 3.4) in July, and IOD index in March provide the best yield forecasting signals for northern, northwestern, and northeastern regions, respectively; (5) wavelet coherence study demonstrated noteworthy in-phase and out-phases coherences between key climatic variables (KCVs) and CDYI anomalies at various time-frequencies in three sub-regions; (6) the random forest (RF) model revealed the IOD as the vital contributing factor of rice yield fluctuations in the country; (6) the multi-factorial model with different LACIs and year as predictors can predict rice yield, with the mean relative error (MRE) in the range of 4.82 to $5.51 \%$ only. The generated knowledge can be used for an early assessment of rice yield and recommend policy directives to ensure food security.

Keywords: Climate-derived yield index, multifactorial model, Indian ocean dipole, climate anomalies,

\section{1. Introduction}

41 Understanding the profound impacts of climate instability on agricultural systems is vital for developing 42 appropriate adaptation strategies (Challinor et al. 2014; Deryng et al. 2014; Moore and Lobell 2014; Siebert 43 and Ewert 2014; Ghose et al. 2021a). ENSO driven climate anomaly can cause crop damage, food insecurity, 44 malnutrition, and even famine and losses of life (Marlier et al. 2013; Iizumi et al. 2014; Salam et al. 2020). 45 Therefore, the teleconnection between large-scale atmospheric oscillations and crop yields have been widely 46 studied at global and regional scales to provide the basis of crop yield forecasting (Falcon et al. 2004; Ray et 47 al. 2012; Iizumi et al. 2014; Huang et al. 2017; Rahman and Islam 2019; Wahiduzzaman and Luo 2020).

Rice is the staple food grain and the most widely grown crop variety in many Asian countries, 49 including Bangladesh. Many studies have examined the effects of ENSO on rice production in different Asian countries (e.g., (Zubair 2002; Selvaraju 2003; Falcon et al. 2004). The studies showed a adverse effect of climate fluctuations on rice production. Zubair (2002) found a detrimental effect of El Nino on rainfall, crop growth and yields in one of the two main cropping seasons (yala season) and a positive effect in another

53 growing season (the maha season) in Sri Lanka. Naylor et al. (2007) showed rice and corn production in 54 Indonesia is susceptible to climate variation linked to ENSO events. Roberts et al. (2009) found a significant 
effect of El Niño on both irrigated and rain-fed rice production in the Phillipines. Many recent studies also showed the adverse effects of El-Niño derived climate variation on agriculture of Malaysia, Thailand and

57 Cambodia (Al-Amin and Alam 2016; Girmay Reda and Tripathi 2016; Vimean Pheakdey et al. 2017). Studies also showed El Niño effects on Bangladesh's agriculture through water shortage, soil depletion, and planting 59 season disruption (Chowdhury 2003). Besides, drought, flood, soil salinity, and cyclone have been described 60 as the ENSO-driven main climatic extremes unfavorably influencing agricultural crop production in 61 Bangladesh (Harun-ur-Rashid and Islam 2007; Islam et al. 2017) Approximately $80 \%$ of the total cultivated area in Bangladesh is transplanted with rice in various seasons, comprising more than $91 \%$ of the total crop production (BBS 2017). In Bangladesh, the Aus (Upland Rainfed) season starts in early March and ends in mid-August. The Aman (wet season) runs from May to late December, while the Boro (dry season-irrigated) runs from mid-November to late May. In the rice-growing seasons, the average yield of rain-fed Aus rice is 2.16 t/ha accounted for over $6.70 \%$ of the total rice production of Bangladesh (BBS 2018). However, the Bangladesh government wants to use the advantage of lower irrigation requirements of Aus rice cultivation to minimize water dependence and increase sustainability in agriculture (Uddin and Dhar 2018; Islam et al. 2019). Therefore, the government has introduced an incentive program recently for small and marginal farmers to rejuvenate the Aus rice cultivation (Uddin and Dhar 2018).

71 Given the significant impact of rice production on agricultural system, livelihood, and food security, it is 72 crucially essential to understand the critical agro-climate parameters and large-scale atmospheric circulation 73 indices for Aus rice yield forecasting for different sub-regional ecotypes of Bangladesh. (Ghose et al. 2021b), while elevated temperatures can increase crop production. However, some studies have shown that crop yield drops significantly when daytime temperatures reach a specific crop-specific threshold

77 (Islam et al. 2019). Each crop has an optimal minimum and maximum temperature, precipitation, and relative humidity limits for its reproductive and vegetative growth stages. The crop yield changes dramatically when 
upper threshold limit. Besides, extreme precipitation can make conditions for waterlogging and flooding, which also reduces crop production.

ENSO effects on rainfall and temperature in Bangladesh has been reported in previous studies (Ahasan et al. 1970; Chowdhury 2003; Wahiduzzaman 2012). However, the effect of ENSO on weather and crop production has only received limited attention in the region. Chowdhury (2003) reported that the climate has a noteworthy association with SOI extremes (despite a poor quantitative correspondence between the strength of ENSO and the rainfall anomaly), negative SOIs with dry and positive SOIs with wet conditions in Bangladesh. In the case of a moderate SOI anomaly, the index-climate relationship, especially in Bangladesh, appeared to be contradictory during the moderate El Nino years' wet season. In recent times, Wahiduzzaman and Luo (2020) suggested a strong relationship of ENSO with precipitation and temperature over the nation. Ghose et al. (2021a) recently revealed an increase in temperature by $1^{\circ} \mathrm{C}$ and rainfall by $1 \%$ cuases a decrease in Aman rice yields by $33.59 \%$ and $3.37 \%$, respectively in southwest and southeastern regions of Bangladesh. They also suggested that rice yield significantly affected by the Indian Ocean Dipole (IOD). However, the linkages vary for regions and seasons. However, no studies have been conducted to evaluate the effect of ENSO on crop yields in Bangladesh, except the study of Ghose et al. (2021a; b).

Because of current anthropogenic climate change, it is essential to recognize effective adaptation alternatives for improving current food production and reducing crop systems' vulnerability to future climatic parameters (Islam et al. 2021). There is also a need to understand the possible linkage of global and regional climate variabilities to crop yield to improve crop yield forecasting capacity. This study aims to assess how ENSO and related climate variability affect rice yield in different subregions of Bangladesh. The ultimate objectives of this work are (1) to evaluate the agro-climatic regionalization of the Aus rice yield in Bangladesh using the principal component analysis of annual climate-derived yield index (CDYI) time series estimated for 23 districts of Bangladesh for the period 1980-2017; (2) to investigate the inter-annual variability of CDYI of Aus rice in different climatic sub-regions using Pearson correlations, multiple regression and wavelet coherence analysis; (4) to identify the key large-scale atmospheric circulation indices (LACIs) affecting the fluctuation of Aus rice yield based on the CDYI-LACI association and random forest model; (5) to predict rice 
yield in three sub-regions of the country using the key LACIs as input in a multi-factorial model. The knowledge of Aus rice yield responses to climate oscillations would facilitate an early assessment of rice yield and recommend policy directives to ensure food security.

\section{Data and Methods}

\subsection{Study area}

Bangladesh is the world's leading deltaic country, situated in the southeastern part of Asia, extending $20.30^{\circ}$ to $26.45^{\circ} \mathrm{N}$ latitudes and $88.00^{\circ}$ to $92.45^{\circ} \mathrm{E}$ longitudes (Fig 1). The total area of this deltaic country is 147,700 . By and large, $80 \%$ land area of this country is the floodplain of three major trans-boundary rivers: the Brahmaputra, the Padma, and the Meghna and their tributaries. The elevation of the floodplain varies from 1 to 60 meters. Hills and hillocks occupy only a small part of southeastern and northeastern regions. The biodiversity-rich Bay of Bengal surrounds the southern part of the country. The country is blessed with a monsoon climate. The monsoon rainfall is an inevitable element for the country's agricultural crop production. Bangladesh has three rice growing seasons: Aus, Aman, and Boro, based on climatic characteristics (Kamruzzaman et al. 2019). The present study is focused on the pre-Kharif Aus rice growing during April-July. The country's average precipitation is about $2400 \mathrm{~mm}$ per year, mainly during June-September (monsoon season). On average sub-tropical monsoon climate dominates the country. However, the western and northwestern part of this country often experiences moderate to extreme droughts due to inter-annual rainfall variability.

The historical daily mean minimum temperature, maximum temperature, relative humidity, wind speed (at $2 \mathrm{~m}$ height), evapotranspiration and net radiation for the whole country are $21.39{ }^{\circ} \mathrm{C}, 29.94{ }^{0} \mathrm{C}, 80 \%$, $1.32 \mathrm{~ms}^{-1}, 3.72 \mathrm{mmd}^{-1}$ and $10.44 \mathrm{MJm}^{-2} \mathrm{~d}^{-1}$, respectively (Salam et al. 2020a). The country is subdivided into seven climatic regions (Fig 1), based on geography and climatology: I) Southeastern; II) Northeastern; III) Northern part of the northern zone; IV) Northwestern; V) Western; VI) Southwestern and VII) South-central. Three out of seven climatic regions, northern part of the northern zone, southwestern and northeastern, were considered in the present study as Aus is widely cultivated in these regions.

\subsection{Data sources}



the period 1980-2017. Besides, monthly cloud cover and potential evapotranspiration data for 18 stations were acquired from the Bangladesh Agricultural Research Council (www://climate.barcapps.gov.bd). The percentage of missing data in the acquired datasets was less than 5\%. The nearest stations' data were used to

137 fill the missing data. The Staff of BMD checked all these data to ensure quality.

Some field observed data were used in this study: crop growth, rice development stages, and yields. Data of the crop growth and Aus rice development stages were acquired from Bangladesh Rice Research Institute (BRRI), and Aus rice yield data (yield/area, M.t/acre) of 23 districts were obtianed from the statistical meteorological stations cover these 23 districts. Moreover, data of the five common atmospheric oscillation indices were also used, which are Indian Ocean Dipole (IOD), East Central Tropical Pacific SST (Nino 3.4), 144 Southern Oscillation Index (SOI), Multivariate ENSO (El Niño-Southern Oscillation) index (MEI) and Central Tropical Pacific SST (Nino 4). These atmospheric indices' data were extracted from the National Oceanic and Atmospheric Association (NOAA) Climate Prediction Center (CPC) Website (http://www.cpc.ncep.noaa.gov/products/preci p/CWlin k/pna/nao.shtml) for the period 1980-2017.

\subsection{Climate-derived yield index (CDYI)}

149 The climate-derived yield index (CDYI) is a common method for assessing climatic variables' impacts on crop yields (Zhao et al. 2015; Huang et al. 2020). The present study adopted this method for exploring the relationship between different climatic variables and Aus rice yield. The CDYI is expressed statistically as:

$$
C I Y i=100 *\left(\frac{Y_{a_{i}}}{Y_{m_{i}}}-1\right)
$$

153 Where, $Y_{a_{i}}$ denotes accurate Aus rice yield, and $Y_{m_{i}}$ denotes the five-year moving average of field-induced Aus 154 rice yield (Li et al., 2018). The CDYI can be expressed by the following equations also:

$$
C I Y I=a \times K C V+b
$$




$$
C I Y I=a \times L A C I+b
$$

157 where $a$ signifies the sensitivity of Aus yield variances to the selected key climatic variables (KCV). The effect of climatic variables on Aus rice yield can be estimated by multiplying $a$ with the linear trend of climatic variables (Huang et al. 2019). Likewise, the effects of the LACI divergences on Aus rice yield can be assessed by multiplying it with LACI's linear trend. Adopting assumptions after Fang (2011), the present study considered three conditions, which are: i) during Aus rice-growing season, the trend of actual Aus rice yield must be equivalents to the management-induced Aus rice yield found from simulation curve; ii) study area plays the main role for changing the factors of the management-induced Aus rice yield, and the variation of actual Aus rice yield varies with climatic variability of the respective area; and iii) the impacts of the KCVs on the Aus rice growth must be analogous to the feature of Aus crop growth and the response of Aus crop to the $\mathrm{KCV}$.

\subsection{Key climatic variables limiting the CDYI of Aus rice}

The field investigation explored the growing period of Aus rice and selected the KCVs, which affect the Aus rice yield. The variables that may affect the Aus rice yield, like field management and soil conditions, were omitted from the analysis. The present study determined the KCVs for seven climatic sub-regions of

171 Bangladesh based on the Pearson correlation coefficient (PCC). The average precipitation (PRE), average

172 temperature (TMP), potential evapotranspiration (PET), average maximum temperature (TMX), average 173 minimum temperature (TMN), and average cloud coverage (CLD) from April to July were estimated during 174 the entire growth period of Aus rice. Finally, the relation between KCVs and the Aus rice CDYI were assessed.

\section{$175 \quad 2.5$ Generating relationships between KCVs and Aus rice CDYI}

176 The present study used multiple linear regression (MLR) to assess the functional relation between KCVs and 177 Aus rice CDYI. The statistical equation of MLR is as follows:

$$
Y=\beta_{0}+\beta_{1} x_{1}+\beta_{2} x_{2}+\cdots \ldots .+\beta_{k} x_{k}
$$

179 where $\mathrm{Y}$ is the CDYI of Aus rice, $\beta_{0}$ is the regression constant, $\beta_{k}$ are the coefficients of partial regression, 180 and $\mathrm{x}_{\mathrm{k}}$ are the KCVs. This regression model is convenient to the scientific community by dint of its user181 friendliness and easiness. 
Weather and climate vary geographically and temporally, and therefore, the impacts of climatic

variables on the crop yields in space and time. The correlation between KCVs and the CDYI of Aus rice in each station was used to demonstrate the comparable mean sub-zone status. However, this representation is not correct for all the sub-zones. Therefore, PCA was used for detecting the spatial variations of KCVs based on the likenesses and contrasts (Polong et al., 2019). In PCA, the non-correlated elements are excluded from the main rotating element to generate principal components (PC). The loadings of PCs indicate the correlation between the accompanying PC scores (PCS) and time-series data (Capra and Scicolone 2012). Based on the outcomes of the PCA analysis of Aus rice CDYI, the present study identified three climatic sub-regions of Aus-rice cultivation.

\subsection{Evaluating spatiotemporal changes of Aus rice CDYI using multi-statistical models}

Pearson's correlation coefficient (PCC) was used for assessing the relationship between the time-frequency alteration connotation between the Aus rice yield and the key LACI (Salam et al. 2020).

The ensemble empirical mode decomposition (EEMD), proposed by Wu \& Huang (2009), was used to decompose the non-linear and non-stationary time series signals into oscillatory modes, called Intrinsic Mode Functions (IMFs) (Adarsh \& Reddy, 2016; Alizadeh et al., 2019). The EEMD was used for detecting the variability of LACI and decomposing the time series data. The EEMD estimates IMF using the following steps: (1) superimpose white noise with the finite amplitude on the original data; (2) estimation of signal variation to get IMF1 implementation of the EEMD; (3) superimpose a noise with the similar amplitude on the original data sequence which has been visible with IMF1; and (4) perform EEMD on the new sequence to obtain IMF2. The abovementioned phases are iterated till various IMFs, and the trend objects are originated. The details of EEMD technique can be observed in the paper of Wu and Huang (2009).

The wavelet transform coherence (WTC) (Guo et al. 2018; Rahman and Islam 2019) was used to find the correlation between two time-series. The WTC measures the covariance magnitude between two timeseries that fluctuates between 0 and $1\left(0 \leq R^{2} \leq 1\right)$, where 0 denotes no consistency and 1 means a flawless consistency (Iqbal et al. 2020). With the increase of the consistency, the symphony of time series variables also increases. The correlation is estimated using the following formula: 
$208 \quad R^{2}(m, n)=\frac{\mid N\left(\left.N^{-1} W_{x y}(m, n)\right|^{2}\right.}{N\left(N^{-1}\left|W_{x}(m, n)\right|^{2} N\left(N^{-1}\left|W_{y}(m, n)\right|^{2}\right.\right.}$

209 The present study utilized WTC for exploring the consistency or correlation between the CDYI of Aus rice and 210 the KCVs.

\section{$211 \quad 2.7$ Random forest model}

212 Nowadays, various machine learning algorithms are commonly used in science, technology, engineering, and 213 mathematics to solve complicated non-linear problems. Random forest (RF), proposed by Breiman (2001), is a 214 supervised algorithm that uses two bagging and random tree algorithms. The RF has been widely employing in 215 the literature for detecting features' importance (Salam and Islam, 2020; Salam et al. 2020b, Rahman and 216 Islam, 2019). This study utilized RF model for exploring the importance of Aus rice CDYI against the LACI. 217 An RF model with 100 trees, 1 execution slot, 7 seeds, and a maximum depth of 1 was used in this study. The 218 scholars constantly use this model for its robustness, reliable outcomes, flexibility, and scientific strength.

219 4. Results

\subsection{Calculation of Aus rice CDYI for Bangladesh}

221 Crop yield data is often not an accurate estimate of a region's yield as it is affected by various management

222 factors. Filters are generally used to remove the intrinsic problem in yield data and estimate the regional field 223 average (Zhao et al. 2017). Therefore, filters were used to estimate CDYI of Aus rice of every district. 224 Different filters, including exponent, power, HP, logarithmic and quadratic, were fitted to CDYI to estimate 225 the average regional CDYI. The estimated regional average CDYI using different filters were correlated with 226 the meteorological disaster indicators. The meteorological disasters considered in this study include drought, 227 flood, cold wave and waterlogging indicators. Three indicators related to each disaster were considered, as 228 described in Table 1. The first indicator of each disaster is the total crop planting area's ratio to the disaster229 affected area. The second indicator is the crop planting area's ratio of the disaster suffered area. The third 230 indicator is the intensity of the disaster or the second to the first indicator ratio. Three indicators of four 231 disasters produced a total of 12 indicators. 
Table 2. The table shows that CDYI has a notable negative association $(r<-0.4)$ with the first two drought indicators, DD1 and DD2 (described in Table 1). These are analogous with the past studies on Aus rice's response to climate change in different sub-regions. Ghose et al. (2021a) found a stronger association of yield with precipitation than the other climatic factors. The average areal CDYI obtained using a high pass (HP)

237 filter showed higher negative associations with DD1 and DD2 than other fitted models'. Therefore, HP filter was used to extract the average CDYI of each of the 23 districts.

\subsection{Regional temporal variability of CDYI using PCA}

PCA of Aus rice CDYI series of 23 districts was used to estimate the variance contributions and eigenvalues.

Fig 2a shows the variance contributions of different PCs. The results showed that the first three PCs were

242 adequate to elaborate on the interannual variations of CDYI for the study period of $1980-2017$. Therefore, the 243 top-loading (> 0.8) of each PC was employed (Fig 2b) for climatic regionalization analysis. The three temporal 244 forms with different CDYI of Aus rice alterations were grouped based on PCA as follows: PC1 represents the northern part of Bangladesh, denoted as region I, PC2 characterizes the southwestern part (region II), and PC3 represents the northeastern part (region III). The strong synchronicity between corresponding regional mean CDYI and PCS are presented in Fig 3. The higher climate-driven yield losses were observed before 1995 for all the regions and also after 2005 in region I.

EEMD revealed several periodic CDYI oscillation in each sub-region (Fig 4). However, there was a noticeable regional variability in the prominent CDYI oscillation modes. The CDYI series exhibited a more noteworthy quasi 6-year fluctuation for northern and northeastern regions, with the IMF2 reaching maximum

252 values ranging from 12.72 to $19.71 \%$ (Fig. 4a, c). On the other hand, the IMF1 of CDYI time series was 87.48\%, demonstrating a quasi 2.75 to 3 years fluctuation in CDYI time series in the northwestern region (Fig.

254 4b). Besides, notable short-term fluctuations were observed in the northern and northeastern regions and 255 medium-range fluctuations in the northwestern region.

\subsection{Connection of CDYI with KCVs and LACIs}


Fig. 5 shows the correlations of Aus rice yield with different KCVs in three sub-regions of the study area. The results showed large variability in the influence of different KCVs in different sub-regions. CDYI showed the strongest association of -0.69 with Apr_PRE in the northern region (region I), the largest correlation $(-0.43)$ with Jul_TMP in the northwestern region (region II), and the highest correlation (-0.47) with May_TMN in the northeastern (region III) (Fig 5a, 5b, 5c). The CDYI correlations were significant seven indices in the northern region at $\mathrm{p}<0.01$. Among them, positive association with Apr_ TMX and Jun_ TMP, and negative association with Apr_ PRE, CLD May_ TMP, TMN, CLD (Fig 5a). In region II, CDYI showed a positive association with Apr_PRE and May_PET and a negative association with Apr_TMP, Jul_ TMP, and TMN at p $<0.01$ (Fig 5b). In region III, only May_ PET showed a significant positive association with CDYI, while Mar_ PET, May_ TMN, PRE, Jun_TMN showed a significant negative association at $\mathrm{p}<0.01$ (Fig 5c). The results indicated higher sensitivity of Aus rice yield to different climate variables in the northern region. TMP for region II, and May_ TMN for region III as the most influencing variable define CDYI fluctuation. These three KCVs showed significant influence on Aus yield at $p<0.05$, indicating substantial sensitivity of Aus rice yield to different climatic variables.

The correlation coefficients between Aus rice CDYI and LACI for the Aus rice-growing season (March to July) were also estimated (Fig 6). The most remarkable CDYI- LACI relationship was noticed for region I

274 (northern region), where its highest negative value was -0.42 and the positive value was more than 0.3 . The 275 maximum positive and negative correlations were 0.33 and -0.40 for regions II and 0.36 and -0.41 for region 276 III, respectively. All the negative association of CDYI with LACIs was significant at $\mathrm{p}<0.01$, indicating the 277 potential of CDYIs in Aus rice yield prediction in the study area. The stepwise multiple regression of CDYI with LACIs identified IOD in April (Apr_IOD), NINA3.4 in July (Jul_NINA3.4) and IOD in March (Mar_ 279 IOD) as the most influencing LACI of Aus rice yield fluctuation in regions I, II and III, respectively (Fig 6). relationship was observed in all three sub-regions. The highest negative correlations between CDYI and IOD_ 

2002-2006, and 2013-2016 in region III (Fig 7c).

The relationship between KCVs and LACIs for 0 to 4 months lags for the study period 1980-2017 is shown in

Fig 8. Many of the KCVs were found significantly correlated to different LACIs with different lag months. The KCV showed a positive relationship with IOD and MEI with lag periods of 0 to 3 months, indicating early forecasting of KCVs, and thus, Aus yield using IOD and MEI. Besides, NINO3.4 and NINO4 showed a significant positive association with May_TMN with a lag of 3 months.

Interestingly, MEI showed a significant negative impact with a lag period of 3-month, and SOI showed no significant influence on Aus yield. Furthermore, except the 3-month lag MEI, there was no discrepant impact of LACI on Aus rice yield. The maximum correlation values of $0.37,0.38$, and 0.39 for MEI, NINO3.4, and IOD, respectively, explaining a potential influence of those LACI on Aus rice yield. However, the dominance of KCVs on LACI varies significantly with time.

\subsection{Impacts of KCVs on rice yield fluctuation}

297 Fig. 9 shows the wavelet transform coherence between KCVs and PCs in three sub-regions of Bangladesh. The 298 arrows unto the right side indicate a positive association (in-phase) between the KCVs and PCs and vice versa. 299 Fig 9a exhibits arrows on the left side, stating a negative (out - phase) relationship between PC1 and PET_Apr 300 during 1985-1990 and 1995-2003 in region I. Fig. 9b shows no significant relationship between PC2 and 301 TMP_Jul in region II (Fig 9b). In region III, a strong significant positive relationship was noticed between PC3 302 and TMN_May in 2 to 4 years (Fig 9c). The red circle in Fig. 9 indicates a correlation value of 0.80 , 303 representing a significant relationship.

304 The RF was used to explore the relative importance of contributing factors. This technique confirmed the 305 significance of the contributing factors of Aus rice yield in Bangladesh. The results presented in Table 3 306 revealed IOD and NINO3.4 as the principal contributing LACIs. The most influencing factors for all three 307 regions was IOD. The NINO3.4 was the second-largest contributing factor of Aus rice variability followed by 

regions.

\subsection{Yield prediction for Aus rice using LACI}

312 The multiple linear regression models were developed to forecast Aus rice yield. Two types of models were developed in this study, multifactor and single-factor model. In the multifactor model, the most influencing

314 LACIs of a sub-region and year were used as input. For example, IOD _ Apr and year were used for

315 multifactor development model in region I. For the single-factor model, the only year was used as input. The 316 multifactor and single-factor models developed for different sub-regions using simple multiple regression 317 analysis are presented in Table 4. The model performance was evaluated using coefficient of determination 318 (R2). The R2 values for multifactor models was highest for region I (0.63), followed by region III (0.60) and region I (0.58). The performance of single-factor model was a less than the multifactor models. The R2 for single factor models for the three sub-regions were in the range of 0.44 to 0.49 . The best performance of single-factor model was in region I, like the multifactor model.

The performance of the models in replicating observed yield in different sub-regions was also evaluated through visual inspection of observed and simulated yield time series (Fig. 10). The figure shows a good analogy between simulated and observed yield series in different sub-regions. The maximum relative error in

325 forecasted yield was higher before 1998. The forecasting precision of the multi-factorial model in region III 326 was best, with the mean relative error (MRE) of only $4.82 \%$, followed by region II with MRE of 5.51\%. The 327 forecasting error was relatively higher in region I than in the other two regions.

\section{Discussions}

The present study evaluated the influence of KCVs and LACIs on Aus rice yield in various sub-regions in the country for the period 1980-2017. Three climatic regions, north, northwest, and northeast, were identified

331 based on different Aus yield response to climate variability. This outcome is analogous to Ghose et al. (2021a).

332 They found six climatic regions, including north, northwest, west, southwest, south-central, southeast, based on the susceptibility of rain-fed rice yield to climate variability for the whole Bangladesh. The present study 
revealed Aus rice yield in the northern part of Bangladesh is more susceptible to climatic anomalies. climate variables' oscillation in the range of 2.75 to 3 year as identified in the northwestern sub-region, while a quasi-6 years fluctuation was found in the northern and northeastern regions. These findings are similar to the finding of Ghose et al. (2021a). The precipitation showed a negative correlation with yield in the northern region. The wavelet coherence analysis outcomes ensured this association (Fig 9a). Sarker et al. (2012) showed a significant relationship between Aus rice yield and precipitation, which agrees with this study. The outcome of this result is also in line with Huang et al. (2018). However, this study's finding is inconsistent with Amin et al. (2015), where insignificantly association Aus rice yield with rainfall has been shown. During the primary stage of Aus growing period, it needs supplementary irrigation (BRRI, 1991). About 10-25\% of the annual precipitation occurs during the pre-monsoon hot season (March-May). This pre-monsoon mean rainfall varies from $200 \mathrm{~mm}$ in the northwest to $800 \mathrm{~mm}$ in the north and the northeast (Cottam, 1997). The extreme droughts in the northern part of Bangladesh, where yearly mean rainfall is relatively less, often brings both water scarcity and long-term environmental calamities (Sheffield et al. 2009).

Mean temperature and minimum temperature were found as the key climatic factor in the northwestern and northeastern regions. These two climatic factors showed negative impacts on Aus rice yield. Sarker et al. (2017) stated that maximum temperature positively influences whether the minimum temperature negatively affects rice yield, which is quite consistent with the results found in this study. Due to the ENSO connected indices, seasonal drought occurs during the El Nino stage (Chen et al. 2018). In the current study, indices like IOD, NINA4, NINA3.4, MEI, and SOI showed a significant relationship with rice yield in different subregions. The most influencing indices were IOD_ Apr, NINA3.4_ Jul, and IOD_ Mar for northern, northwestern and northeastern regions, respectively. This result is similar to Chen et al. (2020), where they found that NINO1+2, PDO, NAO, and SOI strongly influence winter wheat yield in Henan province, North China. Huang et al. (2021) used different LACIs, including NINO3, PDO, TSA, NINO4, and NP as the influencing factors of summer maize yield in Henan province in north China which is also in good agreement with the present study. Ahmad et al. (2019) also identified the CDYI and LACI relationship. A good association between KCVs and LACI in different sub-regions in Bangladesh, found in this current study, 
indicates ENSO-climate associations in Bangladesh. Aus rice yield is most influenced by 0 to 3 month lagged IOD followed by NINO3.4 and SOI. The previous studies showed less dominance of NINO4 and NINO3.4 on rice yield (Li et al., 2015; Lizumi et al., 2014; Ray et al., 2012), which is in line with the present study. Limsakul (2019) also showed a less negative relationship between rice yield and MEI in Thailand.

In Bangladesh, the northern part often experiences Rabi droughts, which are preliminarily connected to MEI and El-Nino (Zhao et al. 2016; Zhang et al. 2014). The emphasizes the demand for adaptation and maintenance of drought during Rabi (winter) season, particularly in March. A significant Aus rice yield deficit, specifically before 1995 in the northern and northwestern zone, while after 2005 in the northern region may be linked to droughts in the region in 1991, 1992, 1994, 1995, 1997, 1998, 2000, 2003, 2005, 2007, 2009 and 2010 (Afrin et al. 2018; Islam et al. 2014; 2017; Shahid and Behrawan 2008). El-Nino occurrences are linked to rice yield's heavy retrenchment during 1994/1995 and 2015/2016, as reported by Rahman et al. (2017).

The mean relative error (MRE) in yield prediction based on the multi-factorial model with LACI and year as input was between 4.82 and $5.78 \%$ for different sub-regions of Bangladesh. The yield forecasting technique with LACI and year as inputs showed powerful aptness, stronger exactness, and easier actions. Overall, the yield forecasting error was high in the northern region. This region experiences prolonged drought, water scarcity, groundwater depletion, and extensive cultivation management (Afrin et al., 2018; Rokonuzzaman et al. 2018). Thus fluctuations of Aus rice yield in the northern region were comparatively larger and more difficult to forecast. There is the precedent that such climate occurrences like drought, flood, and cyclone are the consequences of global warming, bringing catastrophic outcomes to rice yield's retrenchment (Zinat et al. 2020).

\section{Conclusion}

The linkage of Aus rice yield in Bangladesh with large-scale atmospheric oscillation indices is explored in this study. The temporal modes of rice CDYI time series of 23 districts of Bangladesh for the period 1980-2017 identified three analogous sub-regions: north, northwest, and northeast. IOD_Apl, NINA 3.4_July, and IOD_March were recognized as the vital LACIs significantly influencing CDYI in north, northwest and northeast sub-regions, respectively. The higher IOD_Apr causes a more significant rice yield reduction in the 
northern region. The PET_Apl revealed a substantial negative (anti-phase) coherence with yield fluctuations at 0-3 and 9-10 years frequency in the north, whereas the TMN_May depicted a noteworthy positive (in-phase) coherence at 2-4 years frequency in the northeast during 1980-2017. The RF model revealed IOD as the most influencing LACI followed by Nina3.4, MEI, SOI, and Nina4, in describing Aus rice yield fluctuation in the study area. The yield forecasting using LACIs and the year as predictors revealed their potential to predict Aus rice yield in Bangladesh. The new knowledge generated and the novel rice yield forecasting pathway shown in this study would certainly help in mitigating crop loss due to climate variability and climate-resilient sustainable agricultural development in Bangladesh. In future, the influence of other LACIs on Aus rice yield can be evaluated. Besides, state-of-the-art machine learning algorithms can be used for the development of

395 yield forecasting models from LACIs.

\section{Acknowledgement}

397 We greatly acknowledge the Bangladesh Meteorological Department (BMD), Bangladesh Berueau of 398 Statistics (BBS) for providing data for this work.

$399 \quad$ Ethical approval

400 Not applicable

401 Consent to Participate

402 Not applicable

403 Consent to Publish

404 Not applicable

405 Data availability

406 Data are available upon request on the corresponding author

407 Author contributions

408 A.R.M.T.I., and B.G., designed, planned, conceptualized, drafted the original manuscript, and B.G, was 409 involved in statistical analysis, interpretation; S.D., M.K., R.S., and A.E., contributed instrumental setup, 410 data analysis, validation; M.K., and M.A.S., contributed to editing the manuscript, literature review, 411 proofreading; B.G., S.S., R.S., and A.R.M. T.I., were involved in software, mapping, and proofreading 412 during the manuscript drafting stage.

\section{Conflict of interest}




\section{Reference}

1. Adarsh S, Reddy MJ (2016) Multiscale characterization of streamflow and suspended sediment concentration data using Hilbert-Huang transform and time dependent intrinsic correlation analysis. Modeling Earth Systems and Environment, 2(4): 1-17.

2. Afrin R, Hossain F, Mamun SA (2018) Analysis of Drought in the Northern Region of Bangladesh Using Standardized Precipitation Index (SPI). Journal of Environmental Science and Natural Resources, 11(1-2): 199-216.

3. Ahasan M, Chowdhary MA, Quadir D (1970) Variability and Trends of Summer Monsoon Rainfall over Bangladesh. Journal of Hydrology and Meteorology. https://doi.org/10.3126/jhm.v7i1.5612

4. Ahmad S, Abbas G, Ahmed M, Fatima Z, Anjum MA, Rasul G, Khan MA, Hoogenboom G (2019) Climate warming and management impact on the change of phenology of the rice-wheat cropping system in Punjab, Pakistan. J. Fiel. Crop. Resea. 230: 46-61.

5. Al-Amin AQ, Alam GM (2016) Impact of El-Niño on agro-economics in Malaysia and the surrounding regions: An analysis of the events from 1997-98. Asian Journal of Earth Sciences. https://doi.org/10.3923/ajes.2016.1.8

6. Alizadeh F, Roushangar K, Adamowski J (2019) Investigating monthly precipitation variability using a multiscale approach based on ensemble empirical mode decomposition. Paddy and Water Environment, 17(4): 741-759.

7. Amin M, Zhang J, Yang M (2015) Effects of climate change on the yield and cropping area of major food crops: A case of Bangladesh. Sustainability, 7(1): 898-915.

8. BBS (2018) GDP of Bangladesh at 2012-13(P). Government of Bangladesh, Dhaka.

9. BBS (2018) Yearbook of Agricultural Statistics. Yearbook of Agricultural Statistics-2017

10. BBS, SID, MoF (2017) Bangladesh Statistics (2016). Bangladesh Bureau of Statistics Statistics and Informatics Division Ministry of Planning

11. Breiman, L., (2001) Random forests. Machine learning. 45(1): 5-32.

12. BRRI (Bangladesh Rice Research Institute), (1991). Rice Yield and Environmental Data. BRRI, Dhaka, Bangladesh.

13. Capra, A., and Scicolone, B., (2012) Spatiotemporal variability of drought on a short-medium time scale in the Calabria Region (Southern Italy). Theo. App. climato. 110(3): 471-488.

14. Challinor, A.J., Watson, J., Lobell, D.B., (2014). A meta-analysis of crop yield under climate change and adaptation. Nature Climate Change. https://doi.org/10.1038/nclimate2153

15. Chen, X., Wang, S., Hu, Z., (2018). Spatiotemporal characteristics of seasonal precipitation and their relationships with ENSO in Central Asia during 1901-2013. Journal of Geographical 
16. Chen, J., Tian, H., Huang, J., Zhang, J. and Zhang, F., (2020). Climate-driven Yield Variability for Winter Wheat in Henan Province, North China and its Relation to Large-scale Atmospheric Circulation Indices. International Journal of Plant Production, pp.1-13.

17. Chowdhury, M.R., (2003). The El Niño-Southern Oscillation (ENSO) and seasonal flooding Bangladesh. Theoretical and Applied Climatology. https://doi.org/10.1007/s00704-003-0001-z

18. Cottam, H., (1997). Tea Cultivation in Assam. Colombo. pp: 103-107.

19. Deryng, D., Conway, D., Ramankutty, N., Price, J. and Warren, R., (2014). Global crop yield response to extreme heat stress under multiple climate change futures. Environmental Research Letters, 9(3), p.034011.

20. Fang, S.B., (2011). Exploration of method for discrimination between trend crop yield and climatic fluctuant yield. J. Nat. Disas. 20(6), 13-18 (in Chinese).

21. Falcon, W.P., Naylor, R.L., Smith, W.L., Burke, M.B. and McCullough, E.B., (2004). Using climate models to improve Indonesian food security. Bulletin of Indonesian Economic Studies, 40(3), pp.355377.

22. Ghose, B., Islam, A.R.M.T., Islam, H.T., Hasanuzzaman, M., Huang, J., Hu, Z., Moniruzzaman, M., Gustave, W., Karim, M. and Ibrahim, S.M., (2021a). Rain-fed rice yield fluctuation to climatic anomalies in Bangladesh. International Journal of Plant Production, pp.1-19.

23. Ghose, B., Islam, A.R.M.T., Kamruzzaman, M., Moniruzzaman, M. and Hu, Z., (2021b). Climateinduced rice yield anomalies linked to large-scale atmospheric circulation in Bangladesh using multistatistical modeling. Theoretical and Applied Climatology, pp.1-23.

24. Reda, A.G., Tripathi, N.K., Soni, P. and Tipdecho, T., (2015). Rain fed rice agriculture under climate variability in Southeast Asia: The case of Thailand. Journal of Earth Science \& Climatic Change, 6(8), p.1.

25. Guo, A., Chang, J., Wang, Y., Huang, Q., Guo, Z., Zhou, S., (2018) Bivariate frequency analysis of flood and extreme precipitation under changing environment: case study in catchments of the Loess Plateau, China. Stoch. Env. R. Ri. Asse. 32(7): 2057-2074.

26. Harun-ur-Rashid, M. and Islam, M.S., (2007). Adaptation to climate change for sustainable development of Bangladesh agriculture. Bangladesh Agriculture Research Institute, pp.1-12.

27. Huang, J., Islam, A.R.M.T., Zhang, F., Hu, Z., (2017). Spatiotemporal analysis the precipitation extremes affecting rice yield in Jiangsu province, southeast China. International Journal of Biometeorology. https://doi.org/10.1007/s00484-017-1372-7

28. Huang, J., Zhou, L., Zhang, F., Li, Y., (2020). Responses of Yield Fluctuation of Winter Oilseed Rape to Climate Anomalies in South China at Provincial Scale. Int. J. P. Prod. 1-10.

29. Huang, J., Ma, H., Sedano, F., Lewis, P., Liang, S., Wu, Q., Su, W., Zhang, X. and Zhu, D., (2019). Evaluation of regional estimates of winter wheat yield by assimilating three remotely sensed reflectance datasets into the coupled WOFOST-PROSAIL model. Eur. J. Agr. 102, 1-13. 
30. Huang, J., Zhang, F., Zhou, L., Hu, Z. and Li, Y., (2018). Regional changes of climate extremes and its effect on rice yield in Jiangsu province, southeast China. Environmental earth sciences, 77(3), pp.111.

31. Huang, J., Zhou, L., Zhang, F. and Li, Y., (2020). Responses of Yield Fluctuation of Winter Oilseed Rape to Climate Anomalies in South China at Provincial Scale. Int. J. P. Prod. 1-10.

32. Huang, J., Zhou, L., Zhang, F., Hu, Z. and Tian, H., (2021). Responses of yield variability of summer maize in Henan province, north China, to large-scale atmospheric circulation anomalies. Theoretical and Applied Climatology, 143(3), pp.1655-1665.

33. Iizumi, T., Luo, J.J., Challinor, A.J., Sakurai, G., Yokozawa, M., Sakuma, H., Brown, M.E. and Yamagata, T., (2014). Impacts of El Niño Southern Oscillation on the global yields of major crops. Nature communications, 5(1), pp.1-7.

34. Iqbal, N., Fareed, Z., Shahzad, F., He, X., Shahzad, U. and Lina, M., (2020). Nexus between COVID19, temperature and exchange rate in Wuhan City: New findings from Partial and Multiple Wavelet Coherence. Sci. T. Env. 728, 138916.

35. Islam, A.R.M.T., Tasnuva, A., Sarker, S.C., Rahman, M.M., Mondal, M.S.H. and Islam, M.M.U., (2014). Drought in Northern Bangladesh: social, agroecological impact and local perception. Int. J. Eco. 4(3), 150-158.

36. Islam, A.R.M., Shen, S., Hu, Z. and Rahman, M.A., (2017). Drought hazard evaluation in boro paddy cultivated areas of western Bangladesh at current and future climate change conditions. Advances in Meteorology, 2017.

37. Islam, A.T., Shen, S., Yang, S., Hu, Z. and Chu, R., (2019). Assessing recent impacts of climate change on design water requirement of Boro rice season in Bangladesh. Theoretical and Applied Climatology, 138(1), pp.97-113.

38. Islam, A.R.M.T., Karim, M.R. and Mondol, M.A.H., (2021). Appraising trends and forecasting of hydroclimatic variables in the north and northeast regions of Bangladesh. Theoretical and Applied Climatology, 143(1), pp.33-50.

39. Sheffield, J., Andreadis, K.M., Wood, E.F. and Lettenmaier, D.P., (2009). Global and continental drought in the second half of the twentieth century: Severity-area-duration analysis and temporal variability of large-scale events. Journal of Climate, 22(8), pp.1962-1981.

40. Kamruzzaman, M., Hwang, S., Cho, J., Jang, M.W., Jeong, H., (2019). Evaluating the Spatiotemporal Characteristics of Agricultural Drought in Bangladesh Using Effective Drought Index. Water, 11(12): 2437.

41. Li, C., Wang, R.., Xu, J., Luo, Y., Tan, M.L., Jiang, Y., (2018). Analysis of meteorological dryness/wetness features for spring wheat production in the Ili River basin, China. Int. J. Biomet. 62(12): 2197-2204. 
42. Li, Z., Zhu, C., Wu, G., Zheng, C. and Zhang, P., (2015). Spatial pattern and temporal trend of prehistoric human sites and its driving factors in Henan Province, Central China. J. Geo. Sci. 25(9), 1109-1121.

43. Limsakul, A., (2019). Impacts of El Niño-Southern Oscillation (ENSO) on Rice Production in Thailand during 1961-2016. Env. Nat. Res. J. 17(4), 30-42

44. Lizumi, T., Luo, J.J., Challinor, A.J., Sakurai, G., Yokozawa, M., Sakuma, H., Brown, M.E. and Yamagata, T., (2014). Impacts of El Niño Southern Oscillation on the global yields of major crops. Nat. commu. 5(1), 1-7.

45. Marlier, M.E., Defries, R.S., Voulgarakis A., (2013). El Niño and health risks from landscape fire emissions in southeast Asia. Nature Climate Change. https://doi.org/10.1038/nclimate1658

46. Moore, F.C., Lobell, D.B., (2014). Adaptation potential of European agriculture in response to climate change. Nature Climate Change. https://doi.org/10.1038/nclimate2228

47. Naylor, R.L., Battisti, D.S., Vimont, D.J., (2007). Assessing risks of climate variability and climate change for Indonesian rice agriculture. Proceedings of the National Academy of Sciences of the United States of America. https://doi.org/10.1073/pnas.0701825104

48. Polong, F., Chen, H., Sun, S. and Ongoma, V., (2019). Temporal and spatial evolution of the standard precipitation evapotranspiration index (SPEI) in the Tana River Basin, Kenya. Theo. App. Clim.138(1-2), 777-792.

49. Rahman, M.S, Islam, A.R.M.T., (2019). Are precipitation concentration and intensity changing in Bangladesh overtimes? Analysis of the possible causes of changes in precipitation systems. Sci. Total. Environ. 690, 370-387.

50. Rahman, M.A., Kang, S., Nagabhatla, N. and Macnee, R., (2017). Impacts of temperature and rainfall variation on rice productivity in major ecosystems of Bangladesh. Agriculture \& Food Security, 6(1), 10.

51. Ray, D. K., Ramankutty, N., Mueller, N. D., West, P. C. and Foley, J. A., (2012). Recent patterns of crop yield growth and stagnation. Nat. Commun. 3, 1293

52. Roberts, M.G., Dawe, D., Falcon, W.P., Naylor, R.L., (2009). El Niño-southern oscillation impacts on rice production in Luzon, the Philippines. Journal of Applied Meteorology and Climatology. https://doi.org/10.1175/2008JAMC1628.1

53. Rokonuzzaman, M., Rahman, M.A., Yeasmin, M. and Islam, M.A., (2018). Relationship between precipitation and rice production in Rangpur district. Progressive agriculture, 29(1), pp.10-21.

54. Salam, R., Islam, A.R.M.T. and Islam, S., (2019). Spatiotemporal distribution and prediction of groundwater level linked to ENSO teleconnection indices in the northwestern region of Bangladesh. Environment, Development and Sustainability, pp.1-27. 
55. Salam, R., Islam, A.R.M.T., Pham, Q.B., Dehghani, M., Al-Ansari, N. and Linh, N.T.T., (2020b). The optimal alternative for quantifying reference evapotranspiration in climatic sub-regions of Bangladesh. Scientific reports, 10(1), pp.1-21.

56. Sarker, M.A.R., Alam, K. and Gow, J., (2012). Exploring the relationship between climate change and rice yield in Bangladesh: An analysis of time series data. Agricultural Systems, 112, pp.11-16.

57. Sarker, M., Alam, K. and Gow, J., (2017). Performance of rain-fed Aman rice yield in Bangladesh in the presence of climate change. Renewable Agric Food Syst. Sciences 28(9): 1341-1368

58. Selvaraju, R .,(2003). Impact of El Niño-southern oscillation on Indian foodgrain production. International Journal of Climatology. https://doi.org/10.1002/joc.869

59. Shahid, S. and Behrawan, H., (2008). Drought risk assessment in the western part of Bangladesh. Nat. haz. 46(3), 391-413.

60. Siebert, S., Ewert, F., (2014). Future crop production threatened by extreme heat. Environmental Research Letters

61. Uddin, M.T., Dhar, A.R., (2018). Government input support on Aus rice production in Bangladesh: Impact on farmers' food security and poverty situation. Agriculture and Food Security. https://doi.org/10.1186/s40066-018-0167-3

62. Vimean, Pheakdey, D., Dang, Xuan, T., Dang, Khanh, T., (2017). Influence of Climate Factors on Rice Yields in Cambodia. AIMS Geosciences. https://doi.org/10.3934/geosci.2017.4.561

63. Wahiduzzaman,(2012). ENSO connection with monsoon rainfall over Bangladesh. International Journal of Applied Science and Engineering Research. https://doi.org/10.6088/ijaser.0020101003

64. Wahiduzzaman, M., Luo, J.J., (2020). A statistical analysis on the contribution of El Niño-Southern Oscillation to the rainfall and temperature over Bangladesh. Meteorology and Atmospheric Physics. https://doi.org/10.1007/s00703-020-00733-6

65. Wu,Z., Huang, N.E., (2009). Ensemble empirical mode decomposition: a noise-assisted data analysis method. Adv. Adapt. Data Anal. 1 (1): 1-41.

66. Zhang, W., Jin, F.F. and Turner, A., (2014). Increasing autumn drought over southern China associated with ENSO regime shift. Geophy. Res. Le. 41(11), 4020-4026

67. Zhao, J., Guo, J. \& Mu, J., (2015). Exploring the relationships between climatic variables and climateinduced yield of spring maize in Northeast China. Agriculture, Ecosystems \& Environment 207: 7990

68. Zhao, Y., Guo, J., Mao, K., (2017). Spatio-temporal distribution of typical natural disasters and grain disaster losses in China from 1949 to 2015. Acta Geographica Sinica 72 (7): 1261-1276.

69. Zhao, C., Piao, S., Wang, X., Huang, Y., et al., (2016). PlAusible rice yield losses under future climate warming. Nat. Plan. 3, 16202. doi: 10.1038/nplants.2016.202.

70. Zinat, M.R.M., Salam, R., Badhan, M.A., Islam, A.R.M.T., (2020). Appraising drought hazard during Boro rice growing period in western Bangladesh. Int. J. Bio. DOI:10.1007/s00484-020-01949-2. 
71. Zubair, L., (2002). El Niño-Southern oscillation influences on rice production in Sri Lanka. International Journal of Climatology. https://doi.org/10.1002/joc.714 

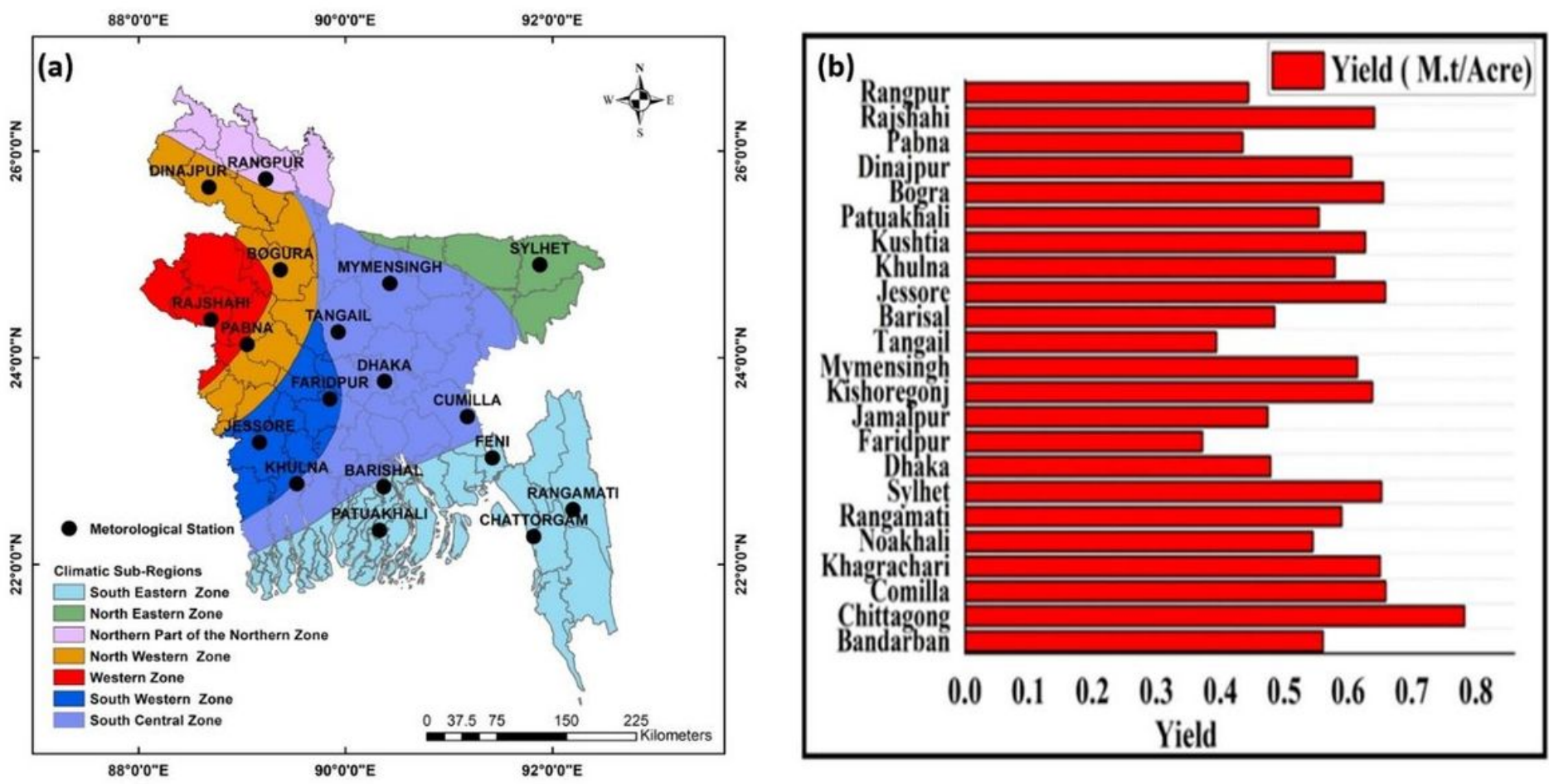

Figure 1

(a) Location of meteorological stations and climatic sub-regions of Bangladesh; (b) Overview of Aus rice production in different districts of Bangladesh Note: The designations employed and the presentation of the material on this map do not imply the expression of any opinion whatsoever on the part of Research Square concerning the legal status of any country, territory, city or area or of its authorities, or concerning the delimitation of its frontiers or boundaries. This map has been provided by the authors. 


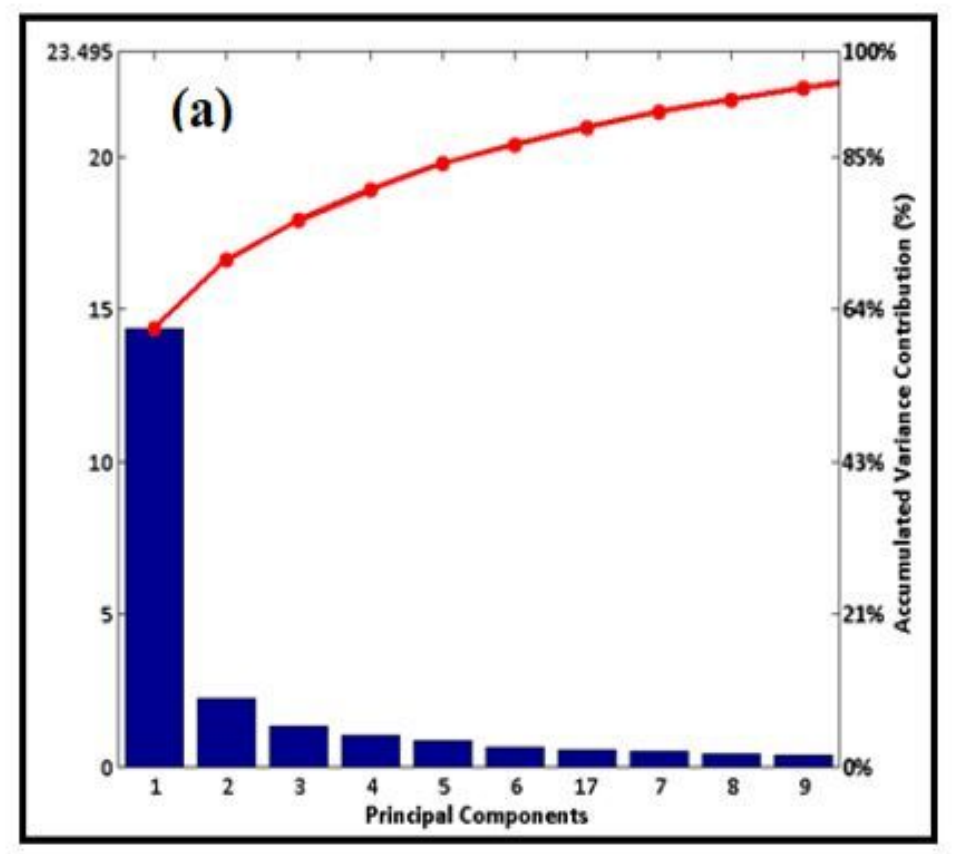

\begin{tabular}{|l|c|c|c|}
\hline (b) & PC1 & PC2 & PC3 \\
\hline Rangpur & 0.91 & -0.59 & 0.09 \\
Dinajpur & 0.31 & 0.81 & 0.03 \\
\hline Bogura & 0.03 & 0.87 & 0.37 \\
\hline Pabua & 0.17 & 0.91 & -0.04 \\
\hline Kushtia & 0.31 & 0.83 & 0.2 \\
Rajshahi & 0.38 & -0.58 & 0.22 \\
\hline Jashosre & 0.18 & 0.01 & -0.07 \\
Khulna & -0.12 & 0.16 & -0.02 \\
\hline Faridpur & -0.06 & 0.42 & 0.4 \\
\hline Jamalpur & -0.42 & 0.19 & -0.05 \\
\hline Mymensingh & -0.28 & 0.28 & -0.01 \\
\hline Tangail & 0.23 & -0.58 & -0.37 \\
\hline Kishoregonj & 0.26 & 0.15 & 0.31 \\
\hline Barisal & 0.06 & -0.19 & -0.21 \\
\hline Dhaka & 0.13 & -0.15 & -0.01 \\
\hline Comilla & 0.34 & -0.73 & -0.3 \\
\hline Sylhet & -0.33 & 0.41 & 0.89 \\
\hline Khagrachari & 0.05 & -0.26 & 0.17 \\
\hline Noakhali & -0.36 & 0.11 & 0.16 \\
\hline Patuakhali & 0.15 & -0.08 & 0.06 \\
\hline Rangamati & 0.25 & -0.49 & -0.23 \\
\hline Bandarban & 0.17 & 0.04 & -0.15 \\
\hline Chattogram & -0.05 & 0.06 & 0.3 \\
\hline & & & \\
\hline
\end{tabular}

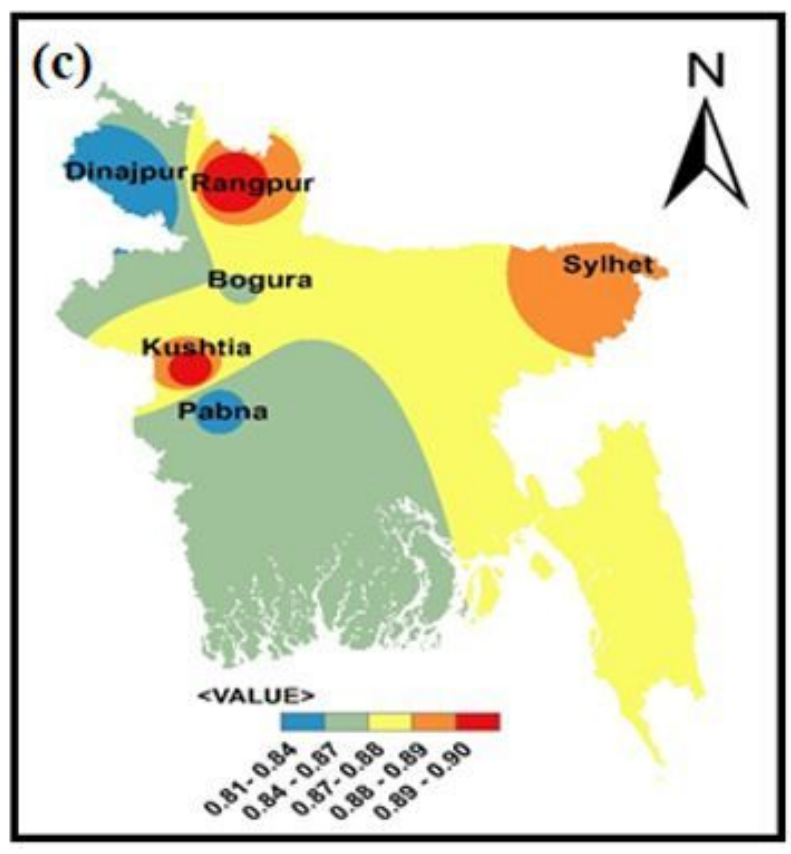

Figure 2

(a) Results of PCA of the annual CDYI time series in 23 districts. a: eigenvalues and explained variances by different principal components (PCs); (b): loading patterns of three first PCs of CDYI series in each district; (c): climatic regionalization based on PCA loadings. Note: The designations employed and the presentation of the material on this map do not imply the expression of any opinion whatsoever on the part of Research Square concerning the legal status of any country, territory, city or area or of its authorities, or concerning the delimitation of its frontiers or boundaries. This map has been provided by the authors. 


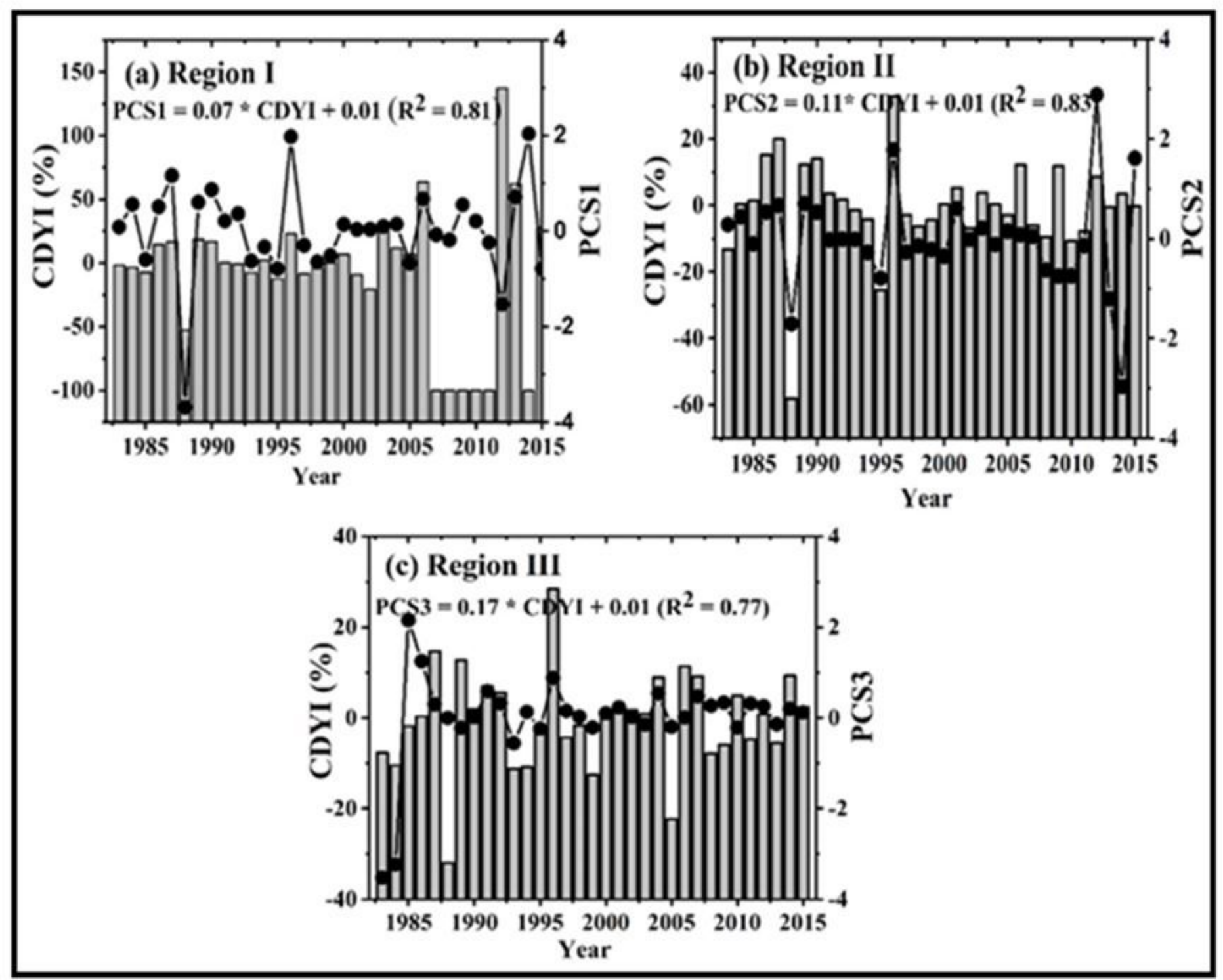

Figure 3

Annual time series of PCs and regional average CDYI in three sub-regions during the observation period $(1980-2017)$ 


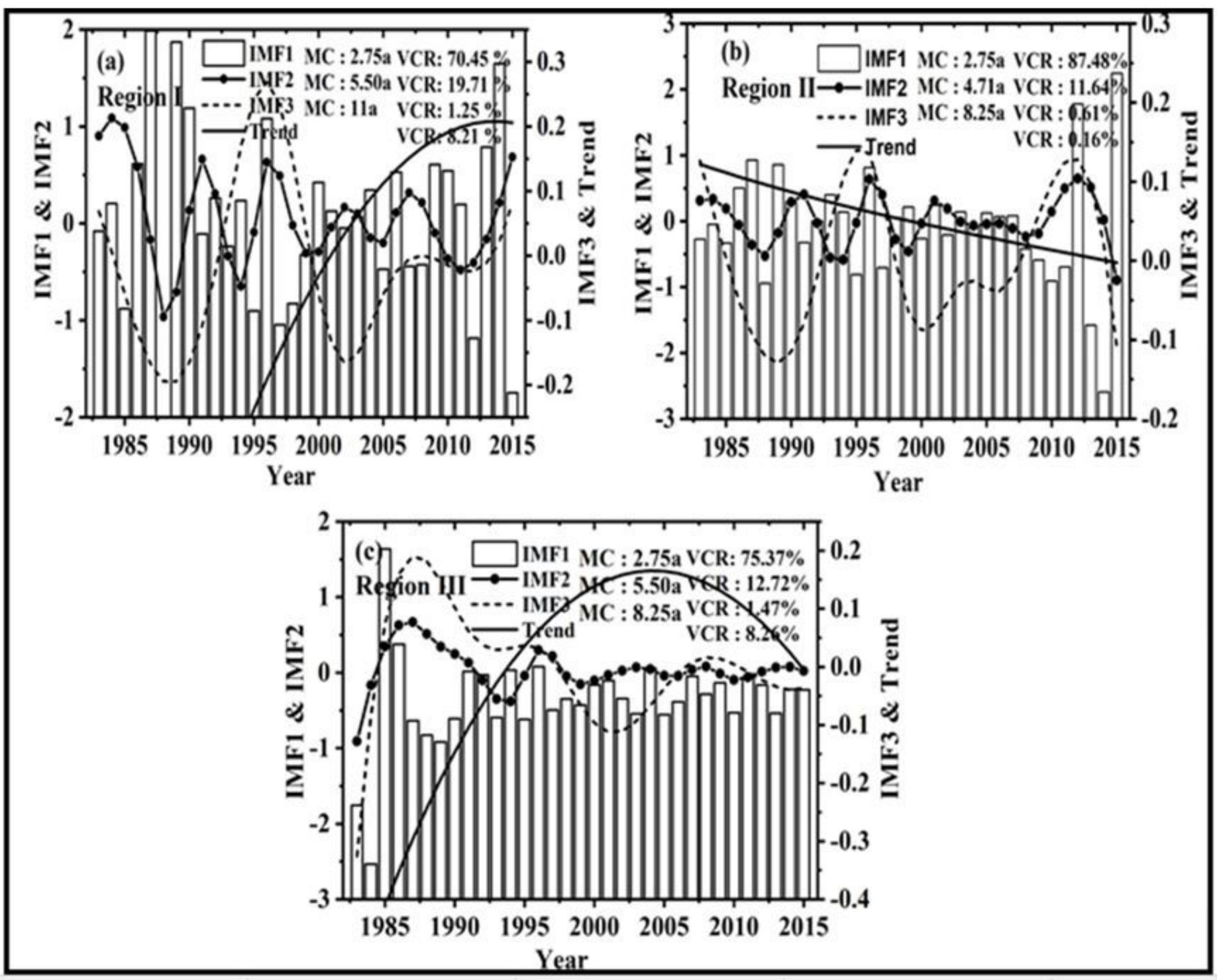

Figure 4

Major cycles (MC) in regional CDYI and their contributions to CDYI variance 


\begin{tabular}{|c|c|c|c|c|c|c|}
\hline (a) & TMX & TMP & TMN & PET & PRE & CLD \\
\hline March & 0.1 & 0.05 & -0.07 & 0.04 & 0.01 & 0.1 \\
\hline April & 0.44 & 0.19 & 0.01 & 0.13 & -0.69 & -0.68 \\
\hline May & 0.05 & -0.45 & -0.33 & 0.02 & 0.08 & -0.42 \\
\hline June & 0.17 & 0.37 & 0.13 & 0.12 & -0.12 & -0.05 \\
\hline July & 0.02 & 0.01 & 0.03 & 0.01 & 0.12 & 0.1 \\
\hline (b) & TMX & TMP & TMN & PET & PRE & CLD \\
\hline March & 0.1 & -0.09 & -0.16 & 0.09 & -0.11 & -0.03 \\
\hline April & -0.21 & -0.31 & -0.16 & 0.13 & 0.41 & -0.07 \\
\hline May & 0.21 & 0.13 & -0.09 & 0.31 & -0.12 & -0.1 \\
\hline June & -0.01 & -0.03 & -0.12 & -0.13 & -0.03 & -0.11 \\
\hline July & -0.21 & -0.43 & -0.31 & -0.16 & 0.25 & 0.3 \\
\hline (c) & TMX & TMP & TMN & PET & PRE & CLD \\
\hline March & -0.1 & 0.12 & 0.27 & -0.47 & -0.01 & 0.21 \\
\hline April & -0.1 & -0.09 & -0.11 & -0.18 & 0.1 & 0.11 \\
\hline May & 0.23 & 0.23 & -0.47 & 0.33 & -0.42 & -0.21 \\
\hline June & 0.1 & -0.11 & -0.32 & -0.15 & 0.11 & 0.11 \\
\hline July & 0.13 & 0.13 & -0.19 & 0.11 & -0.21 & 0.09 \\
\hline
\end{tabular}

Figure 5

Correlations between Aus rice yield and climate variables in regions (a: Region I, b: Region II c: Region III, the number within a solid line frame indicates; the bold fonts denote the key climate variables (KCVs) affecting yield, estimated using multiple stepwise regression analyze 


\begin{tabular}{|c|c|c|c|c|c|}
\hline (a) & IOD & NINA4 & MEI & NINA3.4 & SOI \\
\hline March & 0.23 & 0.03 & 0.2 & 0.11 & 0.14 \\
\hline April & -0.42 & 0.05 & 0.18 & 0.05 & 0.25 \\
\hline May & 0.13 & 0.38 & 0.01 & 0.09 & 0.22 \\
\hline June & 0.35 & 0.19 & 0.16 & 0.31 & 0.19 \\
\hline July & 0.21 & 0.11 & 0.22 & 0.13 & 0.1 \\
\hline \multicolumn{6}{|l|}{ (b) } \\
\hline March & 0.2 & 0.28 & 0.14 & 0.14 & 0.23 \\
\hline April & 0.11 & 0.14 & 0.31 & 0.22 & 0.1 \\
\hline May & 0.33 & 0.16 & 0.24 & 0.18 & -0.39 \\
\hline June & 0.14 & 0.19 & 0.14 & 0.19 & 0.11 \\
\hline July & 0.19 & 0.2 & 0.11 & -0.4 & 0.15 \\
\hline \multicolumn{6}{|l|}{ (c) } \\
\hline March & -0.41 & 0.21 & 0.11 & 0.24 & 0.28 \\
\hline April & 0.1 & 0.18 & 0.14 & 0.17 & 0.24 \\
\hline May & 0.25 & 0.33 & 0.22 & 0.36 & 0.29 \\
\hline June & 0.33 & 0.24 & 0.24 & 0.21 & 0.24 \\
\hline July & 0.25 & 0.14 & 0.14 & 0.26 & 0.34 \\
\hline
\end{tabular}

Figure 6

Correlation between CDYI and LACls in different sub-regions (a: Region I, b: Region c: Region II, Region III; the solid line frame denote the key LACls screened by the multiple stepwise regression analysis) 


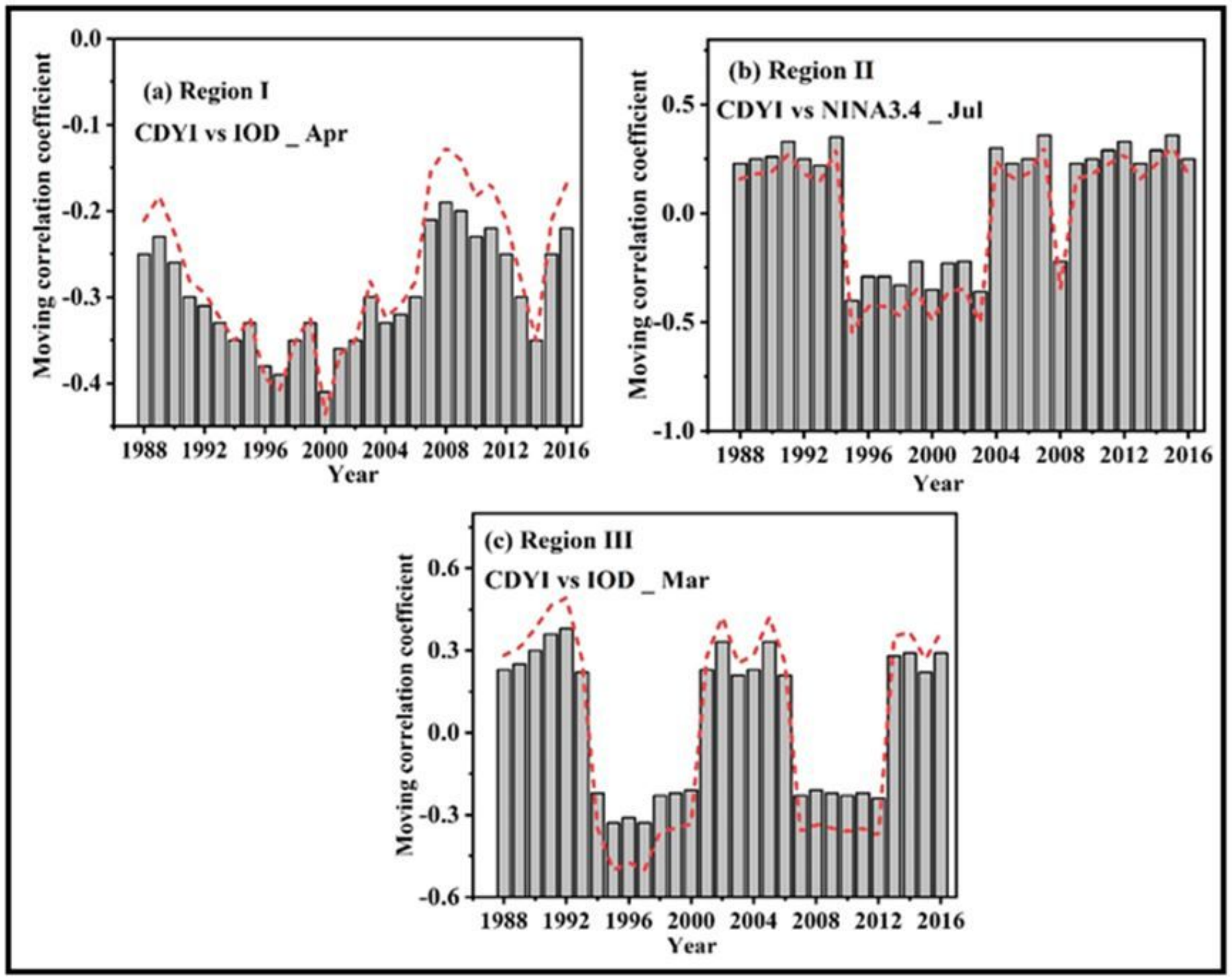

Figure 7

The 10-year moving Pearson correlation series in each sub-region (histograms represent the correlation time series and red dashed lines represent its smooth curve) 


\begin{tabular}{|c|c|c|c|c|c|}
\hline (a) PRE_Apr VS LACI & IOD & MEI & SOI & NINO 3.4 & NINO 4 \\
\hline 4 month & 0.3 & 0.13 & 0.1 & 0.09 & -0.24 \\
\hline 3 month & 0.21 & -0.31 & 0.07 & 0.05 & 0.2 \\
\hline 2 month & 0.29 & 0.37 & 0.18 & -0.15 & 0.12 \\
\hline lmonth & -0.23 & 0.21 & 0.01 & 0.02 & 0.23 \\
\hline 0 month & 0.35 & 0.34 & 0.24 & 0.16 & 0.002 \\
\hline (b) TMP_Jul VS LACI & IOD & MEI & SOI & NINO 3.4 & NINO 4 \\
\hline 4 month & 0.2 & 0.23 & 0.11 & 0.03 & 0.24 \\
\hline 3 month & -0.21 & 0.32 & 0.05 & 0.08 & 0.25 \\
\hline 2 month & 0.2 & 0.14 & 0.28 & -0.13 & 0.11 \\
\hline lmonth & 0.13 & -0.11 & 0.09 & 0.12 & 0.23 \\
\hline 0 month & 0.35 & 0.34 & -0.21 & 0.18 & -0.22 \\
\hline (c) TMN_May VS LACI & IOD & MEI & SOI & NINO 3.4 & NINO 4 \\
\hline 4 month & 0.2 & 0.03 & -0.01 & 0.08 & 0.11 \\
\hline 3 month & 0.21 & 0.35 & 0.15 & 0.38 & 0.35 \\
\hline 2 month & -0.21 & 0.24 & 0.25 & 0.23 & 0.01 \\
\hline lmonth & 0.39 & 0.21 & 0.19 & -0.22 & 0.03 \\
\hline 0 month & 0.05 & -0.14 & 0.14 & -0.21 & 0.21 \\
\hline
\end{tabular}

Figure 8

Correlations between KCVs and LACls in different sub-regions (a: Region I, b: Region II c: Region III, the number within a solid line frame indicates significant correlation at $p<0.01)$. 


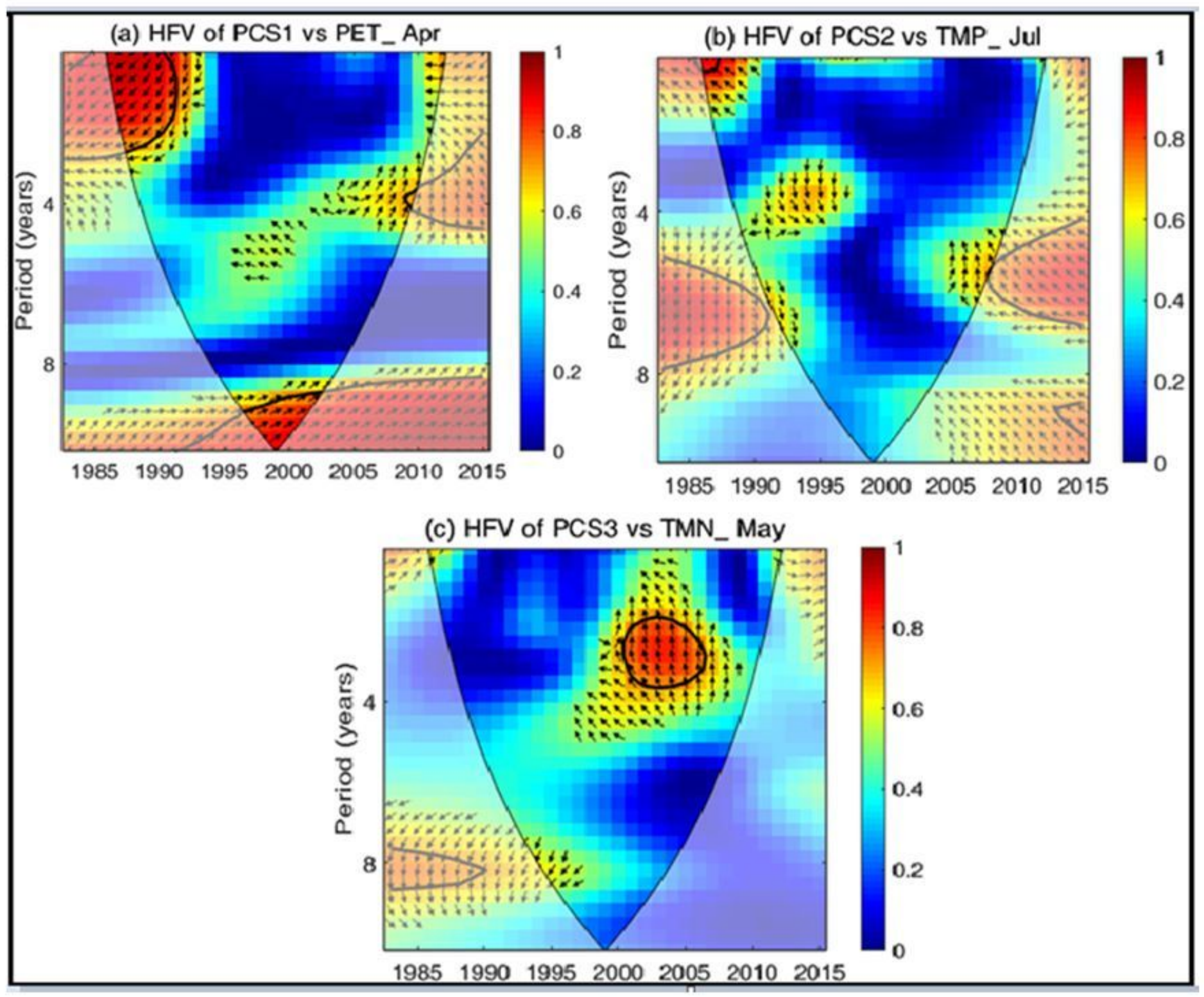

Figure 9

Wavelet coherence and phase difference between PCs and KCVs in different sub-regions (a: Region I, b: Region II, c: Region III). The thick black contour designates the $95 \%$ confidence level against red noise) Note: The designations employed and the presentation of the material on this map do not imply the expression of any opinion whatsoever on the part of Research Square concerning the legal status of any country, territory, city or area or of its authorities, or concerning the delimitation of its frontiers or boundaries. This map has been provided by the authors. 


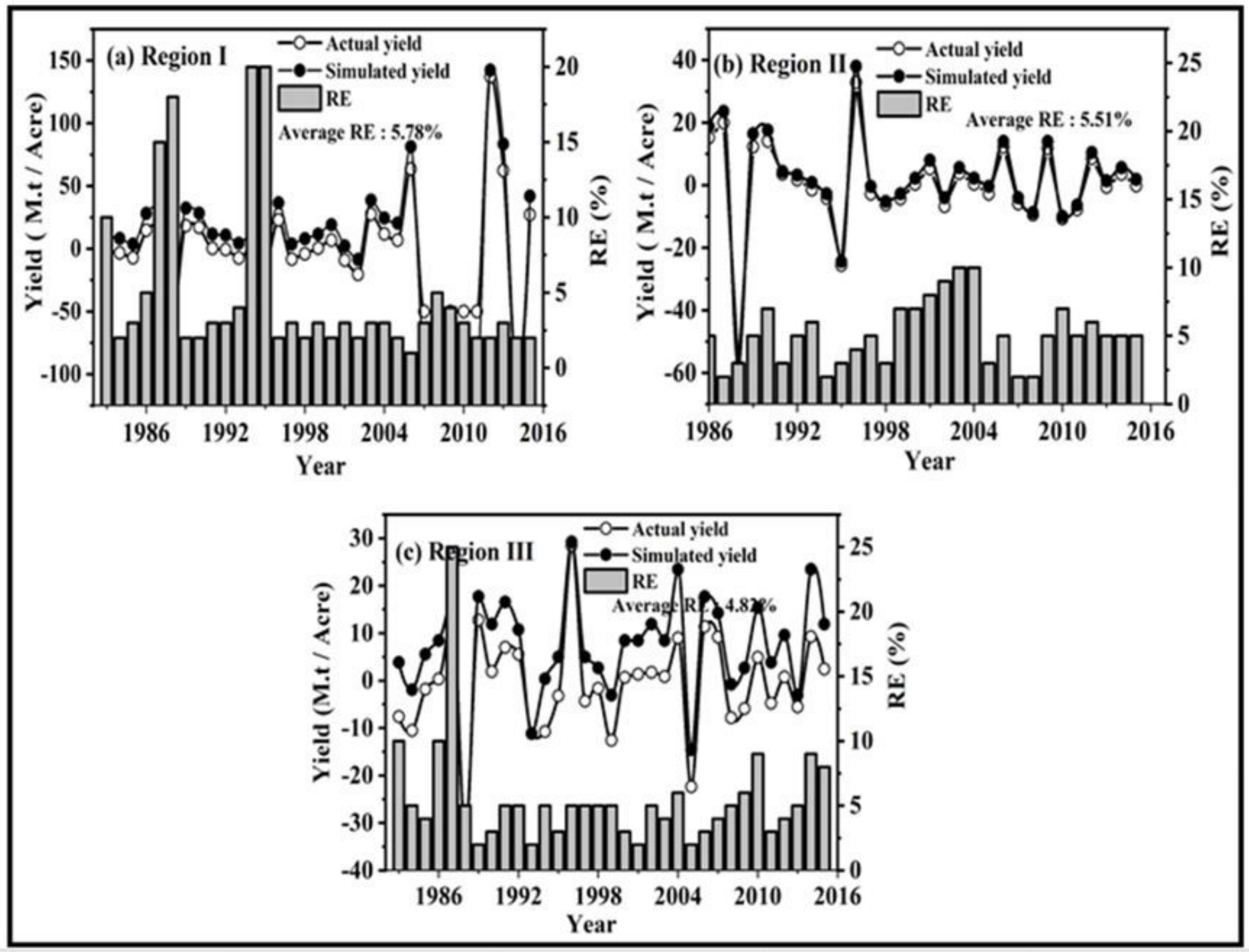

Figure 10

Simulation results for Aus rice yield using multifactorial model 